\title{
Frequency of Diabetic Retinopathy and Factors for Suboptimal Diabetic Control in Type 2 Diabetic Patients in a Trust Hospital of Pakistan
}

\author{
Sidrah Riaz ${ }^{1}$, Tehmina Jahangir ${ }^{2}$, Tariq Khan $^{3}$ \\ Departments of Ophthalmology, ${ }^{1,3}$ Akhtar Saeed Medical and Dental College, Lahore, \\ ${ }^{2}$ Ameer ud Din Medical college, LGH
}

\begin{abstract}
Purpose: To find out the frequency of diabetic retinopathy and factors responsible for poor diabetic control in patients with type 2 diabetes in a trust hospital.

Place and duration of Study: Akhtar Saeed Medical College, from January 2018 to December 2019.

Study Design: Descriptive cross-sectional study.

Methods: Total 395 diabetic patients belonging to lower socioeconomic class were included in the study. Type 1 diabetes, age below 20 years, high myopia, papilledema, dense cataract, corneal scar and patients on dialysis were excluded. Age, gender, duration of disease, family history of diabetes, drugs used for diabetic control, compliance with drug, random serum sugar level at presentation, HBA1c level, best corrected visual acuity, slit lamp and fundus findings were noted.

Results: There were 270 (68.4\%) females and 125 (31.6\%) males (total 395). Random serum sugar was below $200 \mathrm{mg} / \mathrm{dl}$ in $188(47.6 \%)$. Family history of diabetes was positive in $145(36.7 \%)$. Duration of diabetes was below ten years in $288(73 \%)$. Visual acuity was less than $6 / 60$ in $36(6.3 \%)$ patients. HbA1c was within normal range in only 124 (31.4\%). CSMO was present in 199 (50.37\%) patients. Diabetic retinopathy was observed in 57 $(14.43 \%)$ patients. Patients using oral hypoglycemic agents were $225(57 \%)$, on insulin $151(38.23 \%)$ and19 (4.8\%) were using both oral drugs and insulin. Compliance was poor in 294 (74.4\%).

Conclusion: Poor monetary resources compounded with lack of knowledge about disease, misconceptions regarding insulin and imbalanced diet are big hurdles in achieving optimal glycemic control in lower socioeconomic class.
\end{abstract}

Key Words: Diabetic Retinopathy, glycated hemoglobin $(\mathrm{HbA} 1 \mathrm{c})$, blood serum sugar, clinically significant macular edema.

How to Cite this Article: Riaz S, Jahangir T, Khan T. Frequency of Diabetic Retinopathy and Factors for Suboptimal Diabetic Control in Type 2 Diabetic Patients in a Trust Hospital of Pakistan. Pak J Ophthalmol. 2021, 37 (2): 183-187.

Doi: http://doi.org/10.36351/pjo.v37i2.1123

Correspondence: Sidrah Riaz

Department of Ophthalmology

Akhtar Saeed Medical and Dental College

Lahore

Email: sidrah893@hotmail.com

Received: August 24, 2020

Accepted: January 27, 2021

\section{INTRODUCTION}

Diabetes mellitus is a chronic progressive disease whose prevalence is growing globally. ${ }^{1}$ Pakistan currently stands at $7^{\text {th }}$ position among countries with highest diabetic population as estimated by international Diabetic Federation (IDF) database on diabetes and by 2025 it is estimated to be at $5^{\text {th }}$ position. ${ }^{2}$ Diabetes is not a simple disease; it is a 
syndrome, which affects whole human body from head to toe. The major organs affected by it are heart, eyes and kidneys as it is a microangiopathy. Visual impairment due to diabetic retinopathy is not only most serious complication of diabetes but also a leading cause of blindness worldwide. ${ }^{3}$ The longer the duration of diabetes more will be chances of diabetic retinopathy. ${ }^{4}$ According to American Diabetes Association (ADA) about $21 \%$ patients have diabetic retinopathy at time of diagnosis and $60 \%$ develop within a decade of diagnosis. ${ }^{5}$ In 2015 five million diabetes related deaths were reported in low to middle income countries. ${ }^{6}$ Diabetic retinopathy is sight threatening microvascular complication affecting retina. ${ }^{7-9}$ Diabetic patients belonging to low socioeconomic status are more prone to have uncontrolled disease and ocular complications of disease. ${ }^{10}$ Diabetic retinopathy is classified based on absence or presence of new blood vessels.

Rationale of this study was to find out the frequency of diabetic retinopathy in patients presenting in a trust hospital and to find out the factors responsible for poor diabetic control in the lower socio-economic class.

\section{METHODS}

Total three ninety-five (395) diabetic patients were included in the study. All patients were from lower socioeconomic class, which was defined as monthly family income of 20,000 or below. The previously undiagnosed diabetic patients, Type 1 diabetes, age below 20 years, high myopia, papilledema, dense cataract or corneal opacities hindering fundal view and patients on dialysis were not included. The patients included in the study, either presented in Eye OPD with visual complaints or were referred by medical OPD for fundus examination with history of diabetes. The study period was from January 2018 to December 2019. The pupil was dilated with tropicamide $1 \%$ and phenylephrine $10 \%$. The pertinent age, gender, duration of disease, family history of diabetes were noted. They were enquired about drugs used for diabetic control, their compliance with drug and major reasons for poor diabetic control. The random blood sugar level at presentation, HBA1c level, best corrected visual acuity, presence or absence of NVI's, dilated fundus examination findings, presence or absence of clinically significant macular edema (CSMO) and grade of diabetic retinopathy (NPDR or
PDR) were also noted. Fundus examination was done using non-contact fundus lens $(90 \mathrm{D}$; Volk super field). These patients were advised about importance of good diabetic control, visual complications associated with longstanding disease and importance of regular clinical examination by internist and ophthalmologist.

\section{RESULTS}

Out of 395 diabetic patients, $270(68.4 \%)$ were females and 125 (31.6\%) were males. The mean age of diabetic patients was 52.93 years, slightly more for male (55.20 years) patients than females (51.84 years). Mean IOP was $16.24 \mathrm{mmHg}$ in the right eye and 16.54 $\mathrm{mmHg}$ in the left eye. History of laser treatment was seen in $2(0.5 \%)$, Avastin in $8(2 \%)$ and both in 2 $(0.5 \%)$. Further detail is shown in table 1.

Table 1: Details of the patients.

\begin{tabular}{|c|c|c|}
\hline \multicolumn{3}{|l|}{ Gender } \\
\hline Male & 125 & $31.65 \%$ \\
\hline Female & 270 & $68.35 \%$ \\
\hline \multicolumn{3}{|l|}{ Compliance } \\
\hline Poor & 294 & $74.43 \%$ \\
\hline Good & 101 & $25.57 \%$ \\
\hline \multicolumn{3}{|l|}{ Treatment } \\
\hline Oral Drugs & 225 & $56.96 \%$ \\
\hline Insulin & 151 & $38.23 \%$ \\
\hline Both & 19 & $4.81 \%$ \\
\hline \multicolumn{3}{|l|}{ HBA1C } \\
\hline Below 6 & 124 & $31.40 \%$ \\
\hline Above 6 & 271 & $68.60 \%$ \\
\hline Total & 395 & $100 \%$ \\
\hline \multicolumn{3}{|c|}{ Duration of Disease } \\
\hline Above 10 Years & 107 & $27 \%$ \\
\hline Below 10 Years & 288 & $73 \%$ \\
\hline Total & 395 & $100 \%$ \\
\hline \multicolumn{3}{|c|}{ BSR(Random Serum Sugar) } \\
\hline Above 200 & 207 & $52.40 \%$ \\
\hline Below 200 & 188 & $47.60 \%$ \\
\hline Total & 395 & $100.00 \%$ \\
\hline \multicolumn{3}{|l|}{ CSMO } \\
\hline Absent & 196 & $49.63 \%$ \\
\hline Present & 199 & $50.37 \%$ \\
\hline Total & 395 & $100 \%$ \\
\hline \multicolumn{3}{|c|}{ Diabetic Retinopathy } \\
\hline None & 338 & $85.60 \%$ \\
\hline Mild NPDR & 40 & $10.10 \%$ \\
\hline Moderate NPDR & 4 & $1.01 \%$ \\
\hline Severe NPDR & 3 & $0.76 \%$ \\
\hline PDR & 10 & $2.53 \%$ \\
\hline Total & 395 & $100 \%$ \\
\hline \multicolumn{3}{|c|}{ Compliance with Drugs } \\
\hline Good & 101 & $25.60 \%$ \\
\hline Poor & 294 & $74.40 \%$ \\
\hline Total & 395 & $100 \%$ \\
\hline
\end{tabular}




\section{DISCUSSION}

Frequency of diabetic retinopathy in our study was $14.43 \%$. Other countries showed similar statistics i.e. 40\% in Egypt, 42\% in Oman, 25.9\% in Nepal, 3.7\% in South Korea, $27 \%$ in Sri Lanka, $17.6 \%$ in India and $37 \%$ in Iran. ${ }^{11}$ In a review article by Hakeem R et al frequency of diabetic retinopathy was $7.6 \%$ to $11 \% .^{12}$

Diabetic retinopathy (DR) is one of the major causes of decrease vision among diabetic patients. In one study, the diabetic patients were the largest fraction attending eye hospital for visual complaints. ${ }^{13}$ Diabetic retinopathy was more in females in our study which was analogous to results of national diabetes survey of Pakistan. ${ }^{14}$ Nearly one third of patients, $36.7 \%$ had positive family history of diabetes. It was also consistent with other studies in Pakistan and Lebanon, where $30.2 \%$ patients showed positive family history. ${ }^{14,15}$

Clinically significant macular edema (CSMO) is the commonest cause of visual impairment in diabetic patients. ${ }^{16}$ It was observed in $50 \%$ of known diabetic patients who presented in our Eye OPD.

Glycated hemoglobin (HbA1c) is an important indicator to know about optimal diabetic control, which gives information about optimal glycemic control over last 3 months. ${ }^{17,18}$ It was high in majority of our patients.

The increased prevalence of diabetic retinopathy in socioeconomically deprived people was major concern for us. About 24\% Pakistani population is living below national poverty line; $31 \%$ in rural areas and $13 \%$ in urban areas. The systematic review by Kashim et al found poor economy as a major risk factor for nonattendance of retinal clinic by known diabetic patients for regular fundoscopy. ${ }^{19,20}$ Even if they managed to attend the clinic, poor compliance with medical treatment was observed in $74 \%$ our patients. The patients were asked about the possible causes of poor diabetic control. The reasons were misconceptions regarding insulin, lack of knowledge about long term complications of diabetes and nonavailability of balanced diet. It was found that many patients thought that if insulin was suggested by physician for treatment of diabetes it meant that disease had aggravated. Insulin injection storage was also a problem because refrigerator was not available in all homes or temperature maintenance was issues because of frequent power failures. Lack of awareness about disease nature, course and complications was another issue. Another cause of poor diabetic control was poor diet. The diabetic patients diet chart needs specific modification as they need relatively less carbohydrates (50 to $55 \%$ ) in diet than normal nondiabetic person who needs 65 to $75 \% .^{21,22}$ Quality proteins and lipids intake was harder because of affordability issues.

The two densely populated countries in Asia are China and India. Both got independence in 1949 and 1947 respectively and despite facing poverty as a major problem, both have a national plan for diabetic patients. ${ }^{23,24}$ Pakistan, with its 200 million people, lack National Program for diabetes control which is detrimental for our national health and wellbeing. The national action plan on non-communicable diseases (NCD) including diabetes is agreed upon by central government but its implementation is still pending. Furthermore after $18^{\text {th }}$ amendment in constitution in 2010, provinces are mainly responsible for forming own health policies and role of central government is only coordination.

A combined effort by major stake holders; government, health professionals and community are need of time to tackle with diabetic population. Measures should also be taken to deal with poverty at national level to improve people economic status.

The limitations of study are single centered noncomparative study on limited number of patients. Multicentric studies with larger number of diabetic patients are required.

\section{CONCLUSION}

Diabetes mellitus is not only a problem of elite class rather it is also prevalent in patients belonging to low socioeconomic status. Poor monetary resources compounded with lack of knowledge about disease, misconceptions regarding insulin and imbalanced diet are big hurdles in achieving optimal glycemic control.

\section{Ethical Approval}

The study was approved by the Institutional review board/ Ethical review board. (M-19/045/-Ophthal).

\section{Conflict of Interest}

Authors declared no conflict of interest. 


\section{REFERENCES}

1. Akhtar S, Nasir JA, Abbas T, Sarwar A. Diabetes in Pakistan: A systematic review and meta analysis. Pak J Med Sci. 2019; 35 (4): 1173-1178. Doi:10.12669/pjms 35.4.194.

2. International Database Federation Atlas. 2006 showing prevalence of diabetes in 2007 and future projection for 2025. Available from:

http://www.atlas.idf.org/index 1397.html.

3. Jingi AM, Noubiaq JJN, Ellong, Bigna JJR, Myogo CE. Epidemiology and treatment outcomes of diabetic retinopathy in a diabetic population from Cameroon. BMC Ophthalmol. 2014: 19. Doi: 10.1186/1471-241514-19.

4. Lartey SY, Aikins AK. Visual impairment amongst adult diabetics attending a tertiary outpatient department clinic. Ghana Med J. 2018; 52 (2): 84-87. Doi:10.4314/gmj. v52i2.4.

5. Cho N, Shaw J, Karuranga S, Huang Y, da Rocha Fernandes J, Ohlrogge A, et al. IDF diabetes atlas: global estimates of diabetic prevalence for 2017 and projections for 2045. Diabetes res Clin Pract. 2018; 138: 271-281.

6. World Health Organization (WHO) Diabetes country profiles. 2016. Available from:

https://www.who.int/diabetes/countryprofiles/paken.pdf?ua=1.

7. Sivaprasad S, Gupta B, Crosby-Nwaobi R, Evans J. Prevalence of diabetic retinopathy in various ethnic groups: A worldwide perspective. Surv. Ophthalmol. 2012; 57: 347-370.

Doi: 10.1016/j.survophthal.2012.01.004.

8. Yau JWY, Rogers SL, Kawasaki R, Lamoureux EL, Kowalski JW, Bek T, et al. Global prevalence and major risk factors of diabetic retinopathy for the metaanalysis for eye disease (meta-eye) study group. Diabetes Care. 2012; 35: 556-564. Doi: 10.2337/dc111909.

9. Fenwick E, Rees G, Pesudovs K, Dirani M, Kawasaki R, Wong TY, et al. Social and emotional impact of diabetic retinopathy: A review. Clin. Exp. Ophthalmol. 2012; 40: 27-38.

Doi: 10.1111/j.1442-9071.2011.02599.x.

10. Hakeem R, Awan Z, Memon S, Shaikh SA, Sheikh MA, Ilyas S. Diabetic retinopathy awareness and practices in low income suburban population in Karachi, Pakistan. J Diabetol. 2017; 8: 49-55.

Doi: 10.4103/jod.jod_31_17.

11. Mohan V, Unnikrishnan R, Shobana S, Malavika M, Anjana RM, Sudha V. Are excess carbohydrates the main link to diabetes \& its complications in Asians? Indian J Med Res. 2018; 148 (5): 531-538.

Doi: 10.4103/ijmr.IJMR_1698_18.
12. Hakeem R, Fawwad A. Diabetes in Pakistan: Epidemiology, Determinants and Prevention. J Diabitol. 2010; 3: 4.

13. Khan A, Riaz Q, Soomro F, Qidwai U, Qazi U. Frequency and patterns of eye diseases in Retina clinic of a tertiary care hospital in Karachi. Pak J Ophthalmol. 2011; 27: 155-159.

14. Basit A, Fawwad A, Qureshi H, Shera AS. Prevalence of diabetes, pre-diabetes and associated risk factors: second National Diabetes Survey of Pakistan (NDSP), 2016-2017. BMJ Open, 2019; 8 (11): e020961corr1.

15. Mehanna CJ, Abdul Fattah M, Tamim H, Nasrallah MP, Zreik R, Haddad SS, et al. Year Incidence and Progression of Diabetic Retinopathy in Patients with Type II Diabetes in a Tertiary Care Center in Lebanon. J Ophthalmol. 2017; 2017: 9805145.

Doi: 10.1155/2017/9805145. Erratum in: J Ophthalmol. 2018;2018:2424757.

16. Cheung N, Cheung CM, Talks SJ, Wong TY. Management of diabetic macular edema: new insights and global implications of DCRC protocol V. The Royal College of Ophthalmologists, 2019.

Doi: 10.1038/s41433-019-0738-y

17. Aamir AH, Ul-Haq Z, Mahar SA, Qureshi FM, Ahmad I, Jawa A, et al. Diabetes Prevalence Survey of Pakistan (DPS-PAK): prevalence of type 2 diabetes mellitus and prediabetes using HbA1c: a populationbased survey from Pakistan. BMJ Open, 2019; 9 (2): e025300. Doi:10.1136/bmjopen-2018-025300.

18. Owora AH. Commentary: Diagnostic validity and clinical utility of $\mathrm{HbA1c}$ tests for type 2 diabetes mellitus. Curr Diabetes Rev. 2018; 14 (2): 196-199. Doi: $10.2174 / 1573399812666161129154559$.

19. Kashim RM, Newton P, Ojo O. Diabetic Retinopathy Screening: A Systematic Review on Patients' NonAttendance. Int J Environ Res Public Health, 2018; 15 (1): 157. Doi:10.3390/ijerph15010157.

20. Shaikh S, Ursani TJ, Dhiloo KH, Samuel R, Talpur R, Jawad M, et al. Prevalence of diabetic retinopathy and related factors in patients with type 2 diabetes mellitus in Hyderabad and adjoining areas. J Entomol Zool Stud. 2017; 5 (6): 1755-1759.

21. Chaudhury A, Duvoor C, Reddy Dendi VS, Kraleti S, Chada A, Ravilla $\mathbf{R}$, et al. Clinical review of antidiabetic drugs: Implications for Type 2 Diabetes Mellitus management. Front Endocrinal (Lausanne), 2017; 8: 6. Doi: 10.3389/fendo.2017.00006.

22. Shaw JE, Sicree RA, Zimmet PZ. Global estimates of prevalence of diabetes for 2010 and 2030. Diabetes Res Clin Pract. 2010; 87 (1): 4-14.

Doi 10.1016/j.diabres.2009.10.007.

23. Mumtaz SN, Fahim MF, Arslan M, Shaikh SA, Kazi U, Memon MS. Prevalence of diabetic retinopathy in Pakistan; A systematic review. Pak J Med Sci. 2018; 34 (2): 493-500. Doi: 10.12669/pjns.342.13819. 
24. Nishter S, Boerma T, Amjad S, Alam AY, Khalid F, ul Haq I, et al. Pakistan's health system: performance and prospects after the 18th constitutional amendment. Lancet 2013; 381: 2193-2206. Doi 10.1016/SO1406736(13)60019-7.

\section{Authors' Designation and Contribution}

Sidrah Riaz; Associate Professor: Concepts, Design, Literature search, Data acquisition, Data analysis, Statistical analysis, Manuscript preparation, Manuscript review.
Tehmina Jahangir; Associate Professor: Literature search, Manuscript editing, Manuscript review.

Tariq Khan; Professor: Concepts, Design, Literature search.

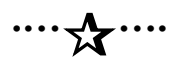

